\title{
Análise da influência do método de cura na evolução da resistência à compressão do concreto com o tempo
}

\author{
C.S. de Faria ${ }^{1 *}$, J.V.F. Altoé ${ }^{1}$, C.L. Pereira ${ }^{1}$, G.S. Veríssimo ${ }^{1}$, M.C. Petrauski ${ }^{2}$ \\ *Autor de Contato: camila.spagnol@ufv.br \\ ${ }^{1}$ Departamento de Engenharia Civil, Universidade Federal de Viçosa, Viçosa, Brasil; \\ ${ }^{2}$ Centro de Ciências Exatas e Tecnológicas, Universidade Estadual do Oeste do Paraná, Cascavel, Brasil.
}

\begin{abstract}
RESUMO
O objetivo deste trabalho foi analisar a influência do método de cura sobre a evolução da resistência à compressão do concreto. Um total de 72 corpos de prova cilíndricos de $10 \times 20 \mathrm{~cm}$ foram moldados de dois concretos com diferentes relações água/cimento, divididos em 3 processos de cura: cura em saco plástico, cura ao ar e cura imersa em solução saturada de hidróxido de cálcio de acordo com a ABNT NBR 5738:2015. Os resultados demonstraram que a cura imersa e a cura em saco plástico promovem uma evolução da resistência à compressão do concreto com valores próximos, ao passo que as amostras curadas ao ar apresentaram resistência bem inferior.
\end{abstract}

Palavras-Chave: concreto; resistência à compressão do concreto; método de cura do concreto. 


\begin{abstract}
The objective of this work was to analyze the influence of the curing method on the evolution of the compressive strength of concrete. A total of 72 cylindrical specimens measuring $10 \times 20 \mathrm{~cm}$ were cast from two concretes with different water/cement ratios, divided into 3 curing processes: curing in a plastic bag, curing in air and immersed curing in a saturated solution of calcium hydroxide, according to ABNT NBR 5738:2015. The results showed that immersed curing and curing in plastic bags promote an evolution of the compressive strength of concrete with similar values, while the samples cured in air showed much lower strength.
\end{abstract}

Keywords: concrete; concrete compressive strength; concrete curing method.

\title{
RESUMEN
}

El objetivo de este trabajo fue analizar la influencia del método de curado en la evolución de la resistencia a la compresión del hormigón. Se moldearon un total de 72 probetas cilíndricas de $10 \times 20 \mathrm{~cm}$ a partir de dos hormigones con diferente relación agua / cemento, divididos en 3 procesos de curado: curado en bolsa plástica, curado al aire y curado sumergido en una solución saturada de hidróxido de calcio, de acuerdo con ABNT NBR 5738:2015. Los resultados mostraron que el curado sumergido y el curado en bolsas plásticas promueven una evolución de la resistencia a la compresión del hormigón con valores similares, mientras que las muestras curadas al aire presentan una resistencia mucho menor.

Palabras clave: hormigón; resistencia a la compresión del hormigón; método de curado de hormigón.

\section{INTRODUÇÃO}

Para efeito da verificação da resistência à compressão do concreto utilizado na construção de estruturas, o método de cura úmida é consagrado, universalmente aceito e prescrito nas principais normas técnicas em diversos países. Entretanto, no contexto da pesquisa experimental, eventualmente são tomadas amostras de um concreto utilizado na confecção de alguma peça e essas amostras são deixadas no laboratório, geralmente no mesmo ambiente, de modo que fiquem expostas às mesmas condições de temperatura e umidade das peças principais.

No âmbito da pesquisa experimental, com frequência os valores da resistência média à compressão e do módulo de elasticidade tangente inicial são de grande interesse, pois são dados de entrada fundamentais para o modelo constitutivo do concreto empregado em simulações numéricas. E, evidentemente, é desejável que os valores medidos desses dois parâmetros sejam representativos do material na estrutura real.

Recentemente, durante um programa experimental no Laboratório de Estruturas da UFV foi realizada a concretagem de dois blocos de concreto, cada um com um volume de aproximadamente $1,0 \mathrm{~m}^{3}$, e foram tomadas amostras do concreto em cilindros de $10 \times 20 \mathrm{~cm}$ para medição da resistência à compressão com 1, 3, 7, 14, 21, 28 e 63 dias, que foram curadas ao ar. Porém ocorreu um fato inusitado: os resultados dos ensaios de compressão simples revelaram que entre os 7 e os 14 dias de idade a resistência do concreto se manteve inalterada. O concreto fora produzido com cimento $\mathrm{CP}-\mathrm{V}$ e durante o período entre os 7 e os 14 dias de idade a temperatura média no laboratório foi de $16,2^{\circ} \mathrm{C}$ e a umidade relativa média foi de $79 \%$. Este fenômeno chamou a atenção dos pesquisadores para a possibilidade de que a cura ao ar estivesse prejudicando severamente a evolução da resistência do concreto, em relação à cura úmida, haja vista que a superfície específica dos cilindros de 10x20 cm era muito diferente da dos blocos maiores. 
Em função do exposto, em duas concretagens subsequentes foram moldados 72 cilindros de $10 \times 20 \mathrm{~cm}$ com o objetivo de se fazer uma avaliação extensiva da evolução da resistência do concreto ao longo do tempo para três métodos de cura distintos, a saber: cura ao ar, cura em sacos plásticos e cura imersa em solução saturada de hidróxido de cálcio de acordo com a ABNT NBR 5738:2015. Concomitantemente, foi realizada uma revisão bibliográfica com o objetivo de levantar resultados e conclusões obtidos por outros autores.

Ferreira Junior (2003) submeteu amostras de concreto a cinco diferentes tipos de cura: cura ao ar, cura úmida de acordo com a ABNT NBR 5738:1994, cura por imersão por um período de 7 dias e cura térmica a vapor sob pressão atmosférica em temperatura de $60^{\circ} \mathrm{C}$ e $80^{\circ} \mathrm{C}$. O autor concluiu que os métodos de cura empregados produziram variações nas propriedades mecânicas e na durabilidade dos concretos, principalmente no que diz respeito à sua estrutura porosa, havendo uma grande dependência da cura em água. A resistência à compressão medida para as amostras curadas ao ar se mostrou bem inferior à das amostras submetidas a cura úmida. Esse efeito foi mais pronunciado para os concretos com CP III do que para os com CP V-ARI. Nos concretos com CP III, nas primeiras idades, a formação dos compostos hidratados foi muito lenta e o ganho de resistência muito pequeno. A cura térmica proporcionou um aumento substancial da resistência mecânica nas primeiras idades. As amostras curadas na temperatura de $80{ }^{\circ} \mathrm{C}$ apresentaram melhores resultados, tanto mecânico, quanto de durabilidade, do que as amostras curadas na temperatura de $60{ }^{\circ} \mathrm{C}$, demonstrando que a hidratação da escória é dependente de um ativador, que, no caso do cimento com elevado teor de escória (CP III), pode ser a cura térmica. O CP V-ARI, por outro lado, possui alta quantidade de clínquer e as reações são ativadas pelo próprio calor de hidratação do clínquer, não sendo necessária a cura térmica como ativador dessas reações. Dessa forma, a cura térmica não se mostrou eficaz para concretos com CP V-ARI. Além disso, a aceleração da hidratação na cura térmica foi mais prejudicial do que benéfica ao concreto, já que provocou um desarranjo microestrutural, afetando as propriedades relacionadas à durabilidade.

Bardella (2005) investigou a influência de diferentes métodos de cura no comportamento mecânico e na durabilidade de amostras de concreto produzidas com CP III 40 E e CP V-ARI - PLUS com adição de sílica ativa em substituição ao $\mathrm{CP}$ na proporção de $10 \%$. $\mathrm{O}$ autor experimentou três tipos de cura: cura ao ar (ambiente de laboratório $-\mathrm{T}_{\text {aprox }}=25^{\circ} \mathrm{C}$ e $\mathrm{U}_{\text {rel }}=65 \%$ ), cura térmica a $60{ }^{\circ} \mathrm{C}$ e cura em água por um período de 7 dias (cura por imersão). A sílica ativa melhorou a resistência à compressão dos concretos em todas as condições de cura utilizadas. Os resultados de resistência dos concretos aos 90 dias com sílica ativa foram cerca de $10 \%$ superiores aos dos concretos sem sílica. O autor também observou que a cura térmica é efetiva principalmente nas primeiras idades dos concretos, porém acarreta menor ganho de resistência a partir dos 28 dias (menor, inclusive, que os CPs curados ao ar). Esse menor ganho de resistência pode ser atribuído a uma distribuição não uniforme dos produtos de hidratação, devido a rápida hidratação inicial dos compostos, ocasionando uma evolução menos acentuada da resistência e aumento da porosidade. Os concretos com CP V-ARI não necessitam de cura térmica, já que este material apresenta uma maior finura e uma quantidade maior de clínquer do que o CP III, desenvolvendo resistências iniciais elevadas sem a aplicação deste método de cura. Os melhores resultados de resistência mecânica e durabilidade foram encontrados nos concretos submetidos à cura imersa. Os piores resultados foram obtidos para os concretos submetidos à cura ambiente.

Silva et al. (2011) moldaram 104 corpos de prova de concreto, sendo 52 de uma dosagem com relação $a / c=0,53$ e os outros $52 \operatorname{com} a / c=0,61$. Metade de cada um desses conjuntos foi submetida a cura imersa em um tanque com água em temperatura ambiente e as demais amostras foram deixadas expostas ao ar livre. Na Tabela 1 são apresentados os percentuais de redução da resistência à compressão das amostras curadas ao ar em relação às amostras que tiveram cura imersa. 
Tabela 1 - Relação entre as resistências à compressão do concreto para cura ao ar e cura imersa.

\begin{tabular}{|c|c|c|c|c|c|c|}
\hline \multirow{2}{*}{ Dias } & \multicolumn{3}{|c|}{ concreto com $\boldsymbol{a} / \boldsymbol{c}=\mathbf{0 , 5 3}$} & \multicolumn{3}{c|}{ concreto com $\boldsymbol{a} / \boldsymbol{c}=\mathbf{0 , 6 1}$} \\
\cline { 2 - 7 } & $\mathbf{7}$ & $\mathbf{2 8}$ & $\mathbf{9 1}$ & $\mathbf{7}$ & $\mathbf{2 8}$ & $\mathbf{9 1}$ \\
\hline $1-\frac{f_{c(\text { ar })}}{f_{c(\text { imers } a)}}$ & $21,1 \%$ & $34,6 \%$ & $41,5 \%$ & $30,9 \%$ & $42,7 \%$ & $44,6 \%$ \\
\hline
\end{tabular}

Silva et al. (2011) analisaram a evolução da resistência de concretos confeccionados com CP V-ARI, com duas relações $a / c$ distintas $(0,35$ e 0,55$)$. Os corpos de prova foram submetidos a 5 tipos de cura: cura em câmara úmida, cura em solução saturada de cal, cura a $10^{\circ} \mathrm{C}$ em câmara climatizada (para simular baixas temperaturas), cura a $40^{\circ} \mathrm{C}$ em estufa e cura a $40^{\circ} \mathrm{C}$ em estufa com os corpos de prova encapados com filme de PVC, de forma a evitar perda de umidade. Os processos de cura nos quais havia saturação do concreto com água geraram os melhores resultados de resistência à compressão (cura úmida e imersa). Em geral, a solução saturada com cal propiciou um ganho de resistência mais elevado. As curas térmicas apresentaram, predominantemente, as menores resistências. Em alguns casos, verificou-se retrocesso de resistência. A cura térmica a $40^{\circ} \mathrm{C}$ acarretou redução do ganho de resistência ao longo do tempo para ambos os concretos.

Szeremeta e Silva (2013) analisaram dois concretos com traços distintos, cujos corpos de prova foram submetidos a cura imersa em solução saturada de cal, a cura química e a cura ao ar livre. Os corpos de prova submetidos a cura imersa ou química apresentaram maiores resistências aos 3, 7 e 28 dias em comparação às amostras curadas ao ar. Os CPs curados ao ar apresentaram resistência à compressão cerca de 52\% inferior aos CPs submersos. As amostras submetidas a cura química apresentaram um ganho de resistência acelerado nos primeiros dias, com maiores resistências aos 3 dias. Porém não apresentaram uma elevada taxa de ganho de resistência até os 28 dias, apresentando, nesta data, resistência $21 \%$ inferior à resistência dos corpos de prova submersos.

Ribeiro et al. (2014) submeteu amostras de um concreto a três tipos de cura: 8 corpos de prova envolvidos em lona plástica; $8 \mathrm{CPs}$ curados ao ar; e $8 \mathrm{CPs}$ curados com imersão total em água. As amostras foram ensaiadas aos 7 e aos 28 dias. O concreto curado ao ar apresentou as menores resistências. $\mathrm{O}$ concreto submetido à cura com lona plástica apresentou resistências intermediárias e o sujeito a cura imersa as maiores resistências (o mesmo foi observado nos ensaios de módulo de elasticidade). A taxa de ganho de resistência dos concretos curado ao ar e em lona plástica, dos 7 aos 28 dias, foi da ordem de $10 \%$ e para o concreto com cura imersa essa taxa foi da ordem de $30 \%$. As resistências à compressão aos 28 dias dos concretos curados ao ar e em lona plástica foram $28 \%$ e $20 \%$ menores, respectivamente, em comparação ao concreto submetido a cura imersa. Os ensaios de absorção e índice de vazios apresentaram maiores valores para o concreto curado ao ar, isto é, este concreto apresenta maior porosidade, sendo, portanto, mais susceptível a patologias e menos durável. O desempenho do concreto envolvido em lona plástica não foi tão bom quanto do concreto submerso, entretanto foi classificado como "durável", seguindo a classificação de Helene (1983). Os resultados evidenciam a influência do procedimento de cura nas propriedades mecânicas e na durabilidade do concreto.

Andrade (2015) submeteu amostras de concretos de pós reativos (CPR) a três diferentes tipos de cura: cura úmida, cura térmica a $90{ }^{\circ} \mathrm{C}$ e cura em autoclave sob temperatura de $150{ }^{\circ} \mathrm{C}$ e pressão de $150 \mathrm{kPa}$. Os três tipos de curas empregados nos CPR influenciam em suas propriedades mecânicas. Os resultados demonstraram que a cura térmica acelera as reações químicas de hidratação do cimento e as reações pozolânicas das adições minerais, devido à elevada temperatura, apresentando, portanto, os maiores valores de resistência à compressão axial. A cura em autoclave 
combina temperatura elevada e pressão, entretanto, não foram observados ganhos significativos de resistência.

Lansini (2016) verificou a influência da temperatura de cura sobre a resistência à compressão de um determinado concreto. As curas foram realizadas em banhos térmicos com temperaturas de $60^{\circ} \mathrm{C}$ (usual na indústria de pré-moldados), $25^{\circ} \mathrm{C}$ (temperatura ambiente média) e $5^{\circ} \mathrm{C}$ (frequente no inverno da região sul do Brasil) sem e com uma manta térmica, utilizada apenas em temperaturas baixas, com objetivo de manter o calor de hidratação. Os resultados mostraram que o concreto curado em temperaturas baixas apresentou baixa resistência à compressão tanto nas primeiras idades quanto aos 28 dias $\left(50 \%\right.$ a $60 \%$ da resistência do concreto sob $25^{\circ} \mathrm{C}$ aos 28 dias). A manta térmica se mostrou pouco eficaz nas primeiras idades (até 7 dias), porém aos 28 dias houve um acréscimo de $10 \%$ na resistência, em relação ao concreto $5^{\circ} \mathrm{C}$ sem manta. Para a cura à temperatura de $60^{\circ} \mathrm{C}$ observou-se um grande crescimento de resistência nas primeiras idades, porém, aos 28 dias, uma resistência menor que para a temperatura intermediária $\left(25^{\circ} \mathrm{C}\right)$, que apresentou a maior taxa de crescimento no intervalo de 7 a 28 dias. O concreto sob temperaturas mais altas tem a hidratação inicial mais rápida; portanto não há tempo para a difusão dos produtos da hidratação para posições mais distantes das partículas de cimento, formando grandes cristais que, posteriormente, não conseguem preencher os espaços intersticiais, aumentando o número de poros na matriz e reduzindo a resistência.

Melo (2017) estudou a influência do tempo e do tipo de cura em 4 dosagens distintas de concreto. As amostras foram divididas em 3 processos de cura: cura imersa em solução saturada de hidróxido de cálcio durante 28 dias, cura ao ar livre pelo método de molhagem (a cada 3 horas) durante 7 dias e durante 3 dias. As diferenças de resistência observadas foram consideráveis. Os corpos de prova de concreto tiveram, em média, uma perda de resistência à compressão de 15,8\%. Os corpos de prova submetidos a cura ao ar livre por molhagem com 3 e 7 dias não apresentaram resultados com diferenças significativas entre si, mas seus valores de resistência à compressão foram cerca de $15,8 \%$ inferiores aos obtidos para as amostras com cura imersa.

Marques (2017) submeteu um concreto com relação $a / c=0,65$ a três tipos de cura: cura ao ar, cura úmida e cura térmica. Os resultados dos ensaios de resistência à compressão mostraram que o concreto curado ao ar apresentou menores resistências aos 3, 7 e 28 dias em comparação à cura úmida e à cura térmica (maiores resistências iniciais). Aos 28 dias, os CPs curados ao ar apresentaram $15 \%$ a menos de resistência que o concreto com cura úmida.

Figueiredo et al. (2019) analisaram a evolução da resistência à compressão de um concreto usinado, cujos corpos de prova foram submetidos a três métodos de cura: cura ao ar (abrigados em local fechado), cura submersa saturada e simulando as condições de cura em obra (molhados durantes 3 dias - 1x ao dia). A partir dos resultados dos ensaios de compressão axial, verificou-se que: nos primeiros dias os concretos curados ao ar e curados nas condições de obra apresentaram maiores resistências, provavelmente devido às altas temperaturas registradas no período, acelerando o processo de hidratação do cimento. A partir dos 7 dias, observou-se um aumento considerável da taxa de ganho de resistência do concreto submerso, que atingiu a maior resistência aos 28 dias.

Assunção et al. (2021) moldaram amostras de concreto com CP II E 32 e as submeteram a 4 tipos de curas: imersão em água saturada de cal (ASHC), imersão em água (AG), ao ar livre (AL) e acondicionada em saco plástico (ASP). As amostras foram ensaiadas aos 7, 14 e 28 dias. As resistências à compressão obtidas para os concretos ASHC e AG foram muito semelhantes e apresentaram os melhores resultados. Aos 28 dias, a diferença foi de 1,73\% com os maiores valores para as amostras na imersão saturada. Os piores resultados observados foram das amostras curadas ao ar livre, que foram cerca de $25 \%$ inferiores aos obtidos para as amostras com cura imersa. O concreto ASP apresentou, em média, resistência à compressão 8,9\% inferior à do ASHC.

Estudos realizados por Mehta e Monteiro (2006) indicam que concretos curados sob condições continuamente úmidas, que permitam a adequada hidratação do cimento e o controle de 
temperatura e umidade do concreto, podem apresentar, após 180 dias, resistência à compressão até três vezes superior à de concretos curados ao ar. Esses autores afirmam, ainda, que é possível ocorrer um pequeno retrocesso da resistência ao longo do tempo em peças esbeltas de concreto submetidas à secagem ao ar.

Neste trabalho, 72 amostras de dois concretos com cimento CP-III-40 RS e relação água/cimento diferentes foram submetidas a três métodos de cura e os valores de resistência à compressão medidos foram analisados em comparação com a resposta de modelos estruturais de vigas mistas de aço e concreto ensaiadas à flexão, e a correspondente resposta numérica obtida com um modelo de elementos finitos.

\section{METODOLOGIA}

\subsection{Generalidades e descrição dos corpos de prova}

Para avaliar quantitativamente a influência do tipo de cura na evolução da resistência do concreto ao longo do tempo, determinou-se a resistência à compressão de corpos de prova submetidos a três diferentes tipos de cura: ao ar, em saco plástico e cura imersa em solução saturada de hidróxido de cálcio, segundo as recomendações normativas da ABNT NBR 5738:2015, todos em ambiente interno.

Foram moldados 72 corpos de prova cilíndricos, com dimensões de 10x20 cm, a partir de dois concretos produzidos no Laboratório de Estruturas da Universidade Federal de Viçosa (UFV). Esses concretos foram empregados na fabricação de 6 exemplares de vigas mistas que seriam ensaiadas à flexão com vistas à validação de um modelo numérico de elementos finitos. Os ensaios ocorreram entre os meses de setembro e dezembro de 2020.

Os concretos produzidos tiveram a seguinte composição: cimento Portland CP-III-40 RS, areia natural quartzosa, brita gnáissica 3/4", água, sílica ativa e aditivos superplastificante (aditivo 01) e retardador de pega (aditivo 02). As propriedades físicas dos materiais estão apresentadas na Tabela 2. A determinação da massa unitária dos agregados foi realizada de acordo com a ABNT NBR NM 45:2006. A massa específica e a absorção dos agregados miúdos foram definidas segundo as especificações da ABNT NBR NM 52:2009 e da ABNT NBR NM 30:2001 e a massa específica dos agregados graúdos, segundo a ABNT NBR NM 53:2009. A determinação da massa específica do cimento Portland e da sílica ativa foi realizada segundo a metodologia prescrita pela ABNT NBR 16605:2017.

Tabela 2 - Propriedades físicas dos materiais.

\begin{tabular}{|c|c|c|c|c|c|c|c|}
\hline Material & $\begin{array}{c}\text { Descrição / } \\
\text { procedência }\end{array}$ & $\begin{array}{c}\text { Massa } \\
\text { específica } \\
\left(\mathbf{k g} / \mathbf{m}^{\mathbf{3}}\right)\end{array}$ & $\begin{array}{c}\text { Absorção } \\
\mathbf{( \% )}\end{array}$ & $\begin{array}{c}\text { Massa } \\
\text { unitária } \\
\left(\mathbf{k g} / \mathbf{m}^{\mathbf{3}}\right)\end{array}$ & $\begin{array}{c}\boldsymbol{D}_{\max } \\
(\mathbf{m m})\end{array}$ & $\begin{array}{c}\text { Módulo } \\
\text { finura }\end{array}$ & $\begin{array}{c}\text { Material } \\
\text { pulverulento } \\
(\%)\end{array}$ \\
\hline Cimento & CP III 40 RS & 3000 & - & - & - & - & - \\
\hline Sílica & Sílica ativa & 2200 & - & - & - & - & - \\
\hline Areia & Natural Quartzosa & 2610 & 0,9 & 1433 & 4,8 & 2,74 & 0,6 \\
\hline Brita & Gnáissica & 2800 & 0,4 & 1440 & 19,0 & 6,59 & 1,9 \\
\hline
\end{tabular}

Foi realizada a análise granulométrica dos agregados miúdos e graúdos, utilizados na produção do concreto, segundo as especificações da ABNT NBR 7211:2019 e de acordo com a metodologia estabelecida pela ABNT NBR NM 248:2003.

Os dois concretos produzidos diferiram apenas pela relação água/cimento $(a / c)$. Para um dos concretos, denominado concreto A, adotou-se uma relação $a / c=0,55$. Para o outro concreto, foi 
utilizada uma relação $a / c=0,60$. Os dois concretos foram dosados para $f_{c k}=40 \mathrm{MPa}$ e um abatimento do tronco de cone de $18 \pm 3 \mathrm{~cm}$ (ver Tabela 3).

Tabela 3 - Traço, relação água/cimento e Slump test dos concretos A e B (frações em massa).

\begin{tabular}{|c|c|c|c|c|c|c|c|c|c|}
\hline Traço & $\begin{array}{c}\text { CP III- } \\
\text { 40 RS }\end{array}$ & Sílica & Areia & Brita & Água & $\begin{array}{c}\text { Aditivo } \\
\mathbf{0 1}(\%)\end{array}$ & $\begin{array}{c}\text { Aditivo } \\
\mathbf{0 2}(\%)\end{array}$ & $\begin{array}{c}\text { Fator } \\
\boldsymbol{a} / \boldsymbol{c}\end{array}$ & $\begin{array}{c}\text { Slump } \\
\text { Test }\end{array}$ \\
\hline $\mathrm{A}$ & 1,0 & 0,09 & 2,66 & 3,19 & 0,49 & 0,43 & 0,43 & 0,55 & 19 \\
\hline $\mathrm{B}$ & 1,0 & 0,09 & 3,03 & 3,48 & 0,50 & 0,43 & 0,43 & 0,60 & 21 \\
\hline
\end{tabular}

A determinação da consistência pelo abatimento do tronco de cone foi realizada conforme as diretrizes da ABNT NBR NM 67:1998. A moldagem, o adensamento, a identificação e a retificação dos corpos de prova foram realizadas seguindo os procedimentos especificados pela ABNT NBR 5738:2015.

Após a desforma das amostras, com 24 horas decorridas após a concretagem, os corpos de prova foram armazenados de acordo com as três metodologias de curas estudadas. Observa-se, na Figura 1, a maneira como os corpos de prova foram moldados e armazenados.

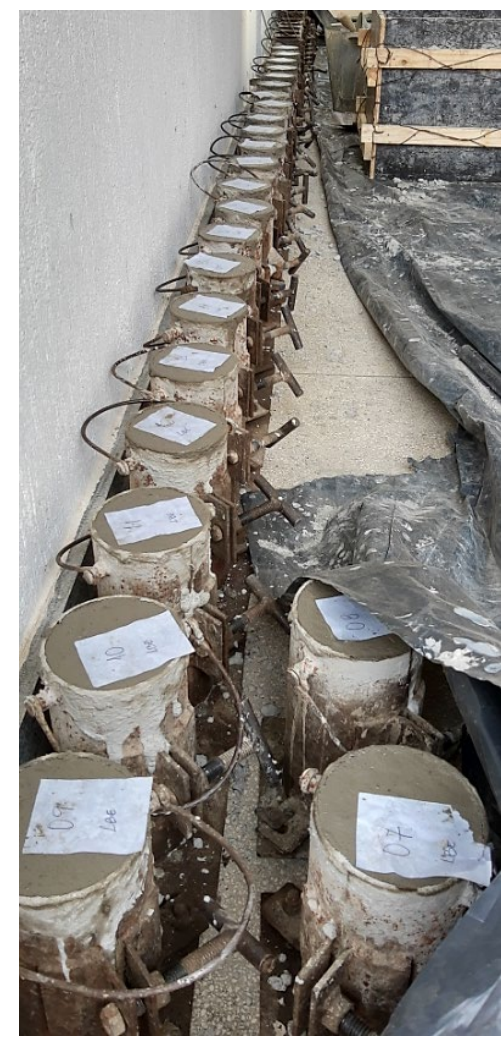

(a)

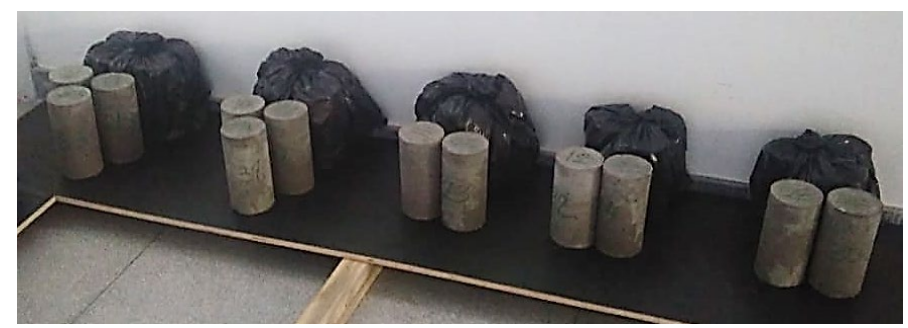

(b)

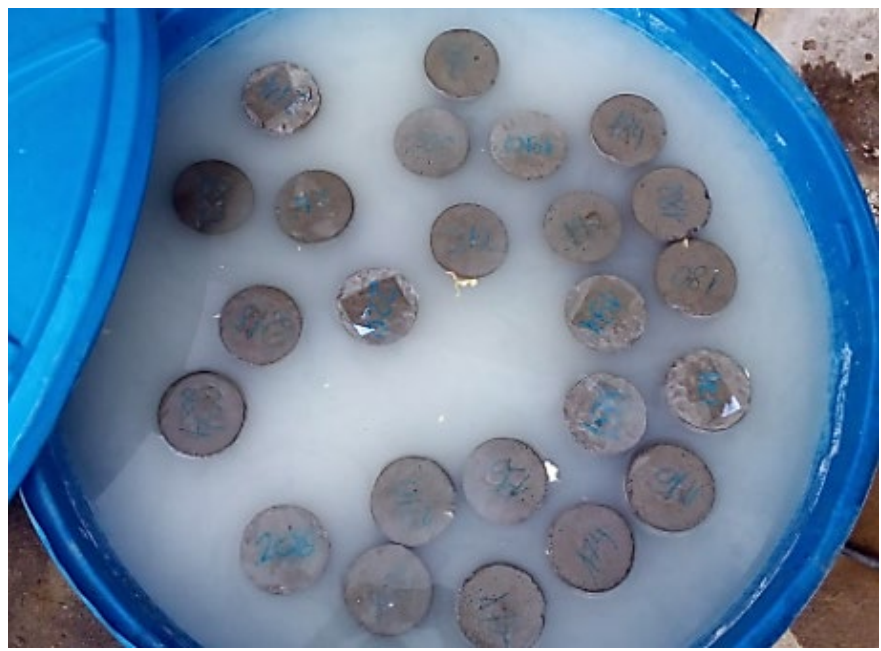

(c)

Figura 1 - Amostragem do concreto. (a) Moldagem dos corpos de prova.

(b) Cura em saco plástico e cura ao ar, em ambiente interno.

(c) Cura imersa em solução saturada de hidróxido de cálcio.

\subsection{Ensaio de resistência à compressão}

Os ensaios de resistência a compressão foram realizados segundo a ABNT NBR 5739:2018. As amostras foram ensaiadas aos 3, 7, 14, 28 e 63 dias. Observa-se, na Figura 2 (b), os exemplares dos 
corpos de prova após a ruptura, sendo o corpo de prova superior curado ao ar e o inferior curado imerso em solução saturada de hidróxido de cálcio.
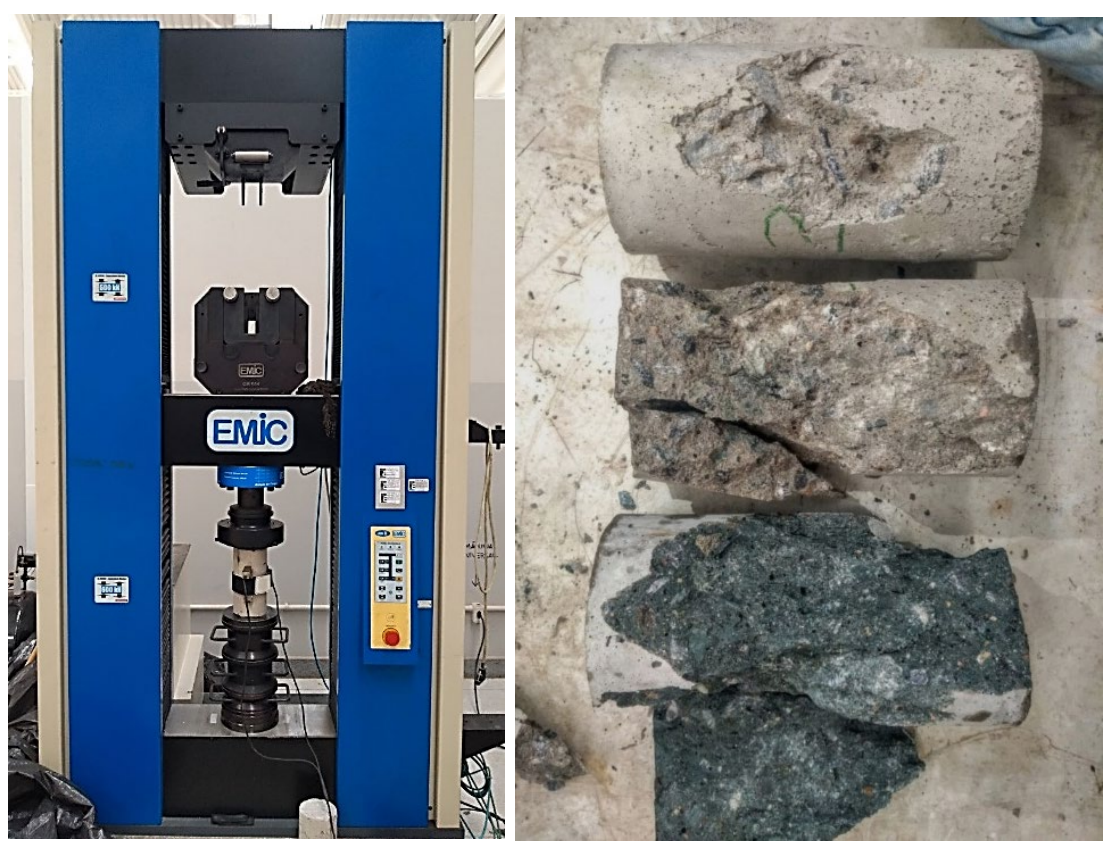

Figura 2 - (a) máquina universal de ensaios;

(b) exemplares dos corpos de prova de concreto após a ruptura.

\section{RESULTADOS E DISCUSSÃO}

Na Tabela 4 estão apresentados os dados dos corpos de prova, bem como os resultados dos ensaios de resistência à compressão axial das amostras dos concretos $\mathrm{A}$ e $\mathrm{B}$, respectivamente. As siglas $\mathrm{CI}$, SP e AR referem-se aos procedimentos de cura imersa, cura em saco plástico e cura ao ar, respectivamente.

A partir dos dados apresentados na Tabela 4, foram calculadas as resistências médias à compressão $f_{c m}$, agrupando os resultados obtidos para as amostras de mesmas idade, relação $a / c$ e tipo de cura. Esses valores estão apresentados nos gráficos da Figura 3 e da Figura 4. 
Tabela 4 - Dados dos corpos de prova.

\begin{tabular}{|c|c|c|c|c|c|c|c|c|c|}
\hline \multicolumn{5}{|c|}{ Concreto A $(a / c=0,55)$} & \multicolumn{5}{|c|}{ Concreto B $(a / c=0,60)$} \\
\hline ID & $\begin{array}{c}\text { Tipo } \\
\text { de } \\
\text { cura }\end{array}$ & $\begin{array}{l}\text { Idade } \\
\text { (dias) }\end{array}$ & $\begin{array}{c}\text { Massa } \\
\text { específica } \\
\left(\mathbf{k g} / \mathbf{m}^{3}\right)\end{array}$ & $\begin{array}{c}f_{c} \\
\text { (MPa) }\end{array}$ & ID & $\begin{array}{c}\text { Tipo } \\
\text { de } \\
\text { cura }\end{array}$ & $\begin{array}{l}\text { Idade } \\
\text { (dias) }\end{array}$ & $\begin{array}{c}\text { Massa } \\
\text { específica } \\
\left(\mathbf{k g} / \mathbf{m}^{3}\right)\end{array}$ & $\begin{array}{c}f_{c} \\
(\mathbf{M P a})\end{array}$ \\
\hline 1 & $\mathrm{CI}$ & 3 & 2344,6 & 14,23 & 37 & $\mathrm{CI}$ & 3 & 2258,5 & 11,37 \\
\hline 2 & $\mathrm{CI}$ & 7 & 2366,2 & 27,88 & 38 & $\mathrm{CI}$ & 7 & 2279,9 & 21,56 \\
\hline 3 & $\mathrm{CI}$ & 14 & 2369,1 & 36,87 & 39 & $\mathrm{CI}$ & 14 & 2284,8 & 30,08 \\
\hline 4 & $\mathrm{CI}$ & 28 & 2375,5 & 42,35 & 40 & $\mathrm{CI}$ & 28 & 2278,2 & 36,11 \\
\hline 5 & SP & 3 & 2333,3 & 16,26 & 41 & SP & 3 & 2292,6 & 11,59 \\
\hline 6 & SP & 7 & 2356,7 & 26,11 & 42 & SP & 7 & 2281,1 & 20,74 \\
\hline 7 & SP & 14 & 2345,7 & 34,73 & 43 & SP & 14 & 2274,5 & 27,52 \\
\hline 8 & SP & 28 & 2372,3 & 38,81 & 44 & SP & 28 & 2292,5 & 31,92 \\
\hline 9 & AR & 3 & 2324,3 & 14,48 & 45 & AR & 3 & 2295,1 & 9,90 \\
\hline 10 & AR & 7 & 2348,7 & 24,82 & 46 & AR & 7 & 2268,4 & 17,09 \\
\hline 11 & AR & 14 & 2318,0 & 29,55 & 47 & AR & 14 & 2281,0 & 24,68 \\
\hline 12 & AR & 28 & 2339,8 & 33,29 & 48 & AR & 28 & 2313,8 & 28,48 \\
\hline 13 & $\mathrm{CI}$ & 3 & 2334,4 & 12,05 & 49 & $\mathrm{CI}$ & 3 & 2231,1 & 9,54 \\
\hline 14 & $\mathrm{CI}$ & 7 & 2357,2 & 23,78 & 50 & $\mathrm{CI}$ & 7 & 2245,8 & 18,79 \\
\hline 15 & $\mathrm{CI}$ & 14 & 2341,6 & 36,95 & 51 & $\mathrm{CI}$ & 14 & 2282,6 & 27,37 \\
\hline 16 & $\mathrm{CI}$ & 28 & 2355,5 & 41,53 & 52 & $\mathrm{CI}$ & 28 & 2305,2 & 32,20 \\
\hline 17 & SP & 3 & 2339,5 & 15,24 & 53 & SP & 3 & 2269,9 & 9,65 \\
\hline 18 & SP & 7 & 2352,3 & 27,55 & 54 & SP & 7 & 2326,2 & 20,78 \\
\hline 19 & SP & 14 & 2315,5 & 32,50 & 55 & SP & 14 & 2302,9 & 24,94 \\
\hline 20 & SP & 28 & 2318,3 & 34,69 & 56 & SP & 28 & 2279,1 & 32,07 \\
\hline 21 & AR & 3 & 2266,3 & 12,66 & 57 & AR & 3 & 2288,9 & 9,40 \\
\hline 22 & AR & 7 & 2255,4 & 21,39 & 58 & AR & 7 & 2254,8 & 17,58 \\
\hline 23 & AR & 14 & 2246,4 & 24,60 & 59 & AR & 14 & 2256,1 & 22,85 \\
\hline 24 & AR & 28 & 2262,0 & 27,83 & 60 & AR & 28 & 2287,5 & 26,84 \\
\hline 25 & $\mathrm{CI}$ & 3 & 2333,9 & 16,34 & 61 & $\mathrm{CI}$ & 3 & 2348,6 & 13,35 \\
\hline 26 & $\mathrm{CI}$ & 7 & 2343,8 & 30,64 & 62 & $\mathrm{CI}$ & 7 & 2370,8 & 26,77 \\
\hline 27 & CI & 63 & 2343,6 & 50,83 & 63 & $\mathrm{CI}$ & 63 & 2273,4 & 42,98 \\
\hline 28 & $\mathrm{CI}$ & 63 & 2351,8 & 52,37 & 64 & $\mathrm{CI}$ & 63 & 2301,8 & 45,97 \\
\hline 29 & SP & 3 & 2323,7 & 16,55 & 65 & SP & 3 & 2332,3 & 14,50 \\
\hline 30 & $\mathrm{SP}$ & 7 & 2339,0 & 30,38 & 66 & SP & 7 & 2346,6 & 26,91 \\
\hline 31 & SP & 63 & 2323,0 & 50,50 & 67 & SP & 63 & 2333,4 & 45,02 \\
\hline 32 & SP & 63 & 2375,6 & 48,20 & 68 & SP & 63 & 2277,2 & 38,69 \\
\hline 33 & AR & 3 & 2303,2 & 13,70 & 69 & AR & 3 & 2234,9 & 12,92 \\
\hline 34 & AR & 7 & 2304,8 & 26,95 & 70 & AR & 7 & 2250,5 & 21,24 \\
\hline 35 & $\mathrm{AR}$ & 63 & 2314,9 & 41,84 & 71 & AR & 63 & 2301,0 & 29,15 \\
\hline 36 & AR & 63 & 2309,6 & 41,75 & 72 & AR & 63 & 2381,3 & 29,17 \\
\hline
\end{tabular}




\section{CONCRETO A}

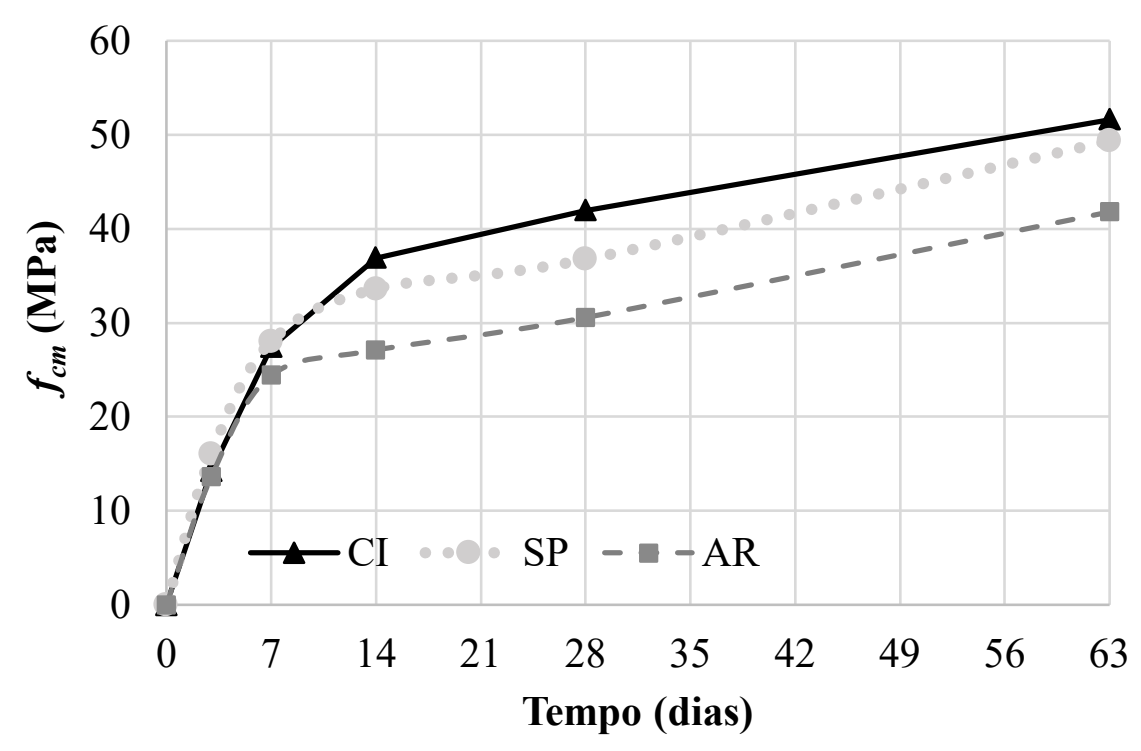

Figura 3 - Resistência média à compressão do concreto A com a idade, por tipo de cura.

\section{CONCRETO B}

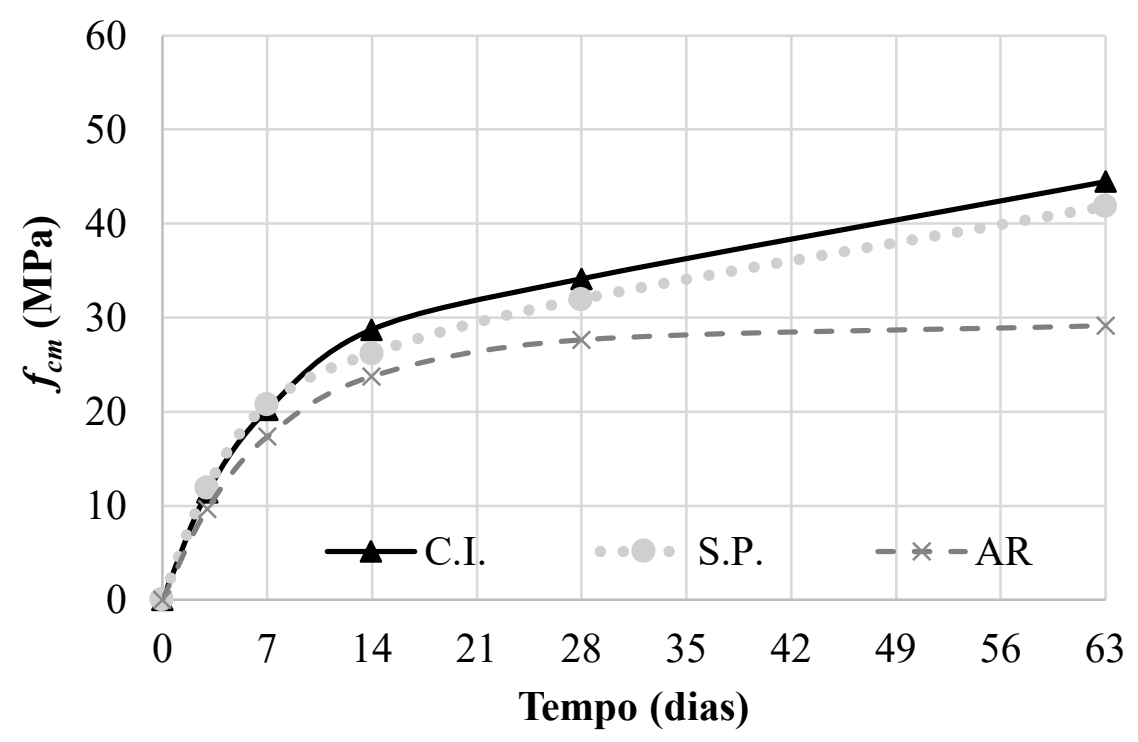

Figura 4 - Resistência média à compressão do concreto B com a idade, por tipo de cura.

As diferenças percentuais entre o procedimento de cura imersa, normatizado pela ABNT NBR 5738:2015, e as curas em saco plástico e ao ar, para cada idade e dosagem do concreto, estão apresentadas na Tabela 5. 
Tabela 5 - Diferenças percentuais entre a cura imersa e as demais curas estudadas.

\begin{tabular}{|c|c|c|c|c|c|}
\hline \multicolumn{2}{|c|}{ Concreto A $(\boldsymbol{a} / \mathbf{c}=\mathbf{0 , 5 5})$} & \multicolumn{2}{c|}{ Concreto B $(\boldsymbol{a} / \mathbf{c}=\mathbf{0 , 6 0})$} \\
\hline $\begin{array}{c}\text { Idade } \\
(\mathbf{d i a s})\end{array}$ & $\frac{\mathbf{S P}}{\mathbf{C I}}$ & $\frac{\mathbf{A R}}{\mathbf{C I}}$ & $\begin{array}{c}\text { Idade } \\
(\mathbf{d i a s})\end{array}$ & $\frac{\mathbf{S P}}{\mathbf{C I}}$ & $\frac{\mathbf{A R}}{\mathbf{C I}}$ \\
\hline 3 & $13 \%$ & $-4 \%$ & 3 & $4 \%$ & $-16 \%$ \\
\hline 7 & $2 \%$ & $-11 \%$ & 7 & $3 \%$ & $-14 \%$ \\
\hline 14 & $-9 \%$ & $-27 \%$ & 14 & $-9 \%$ & $-17 \%$ \\
\hline 28 & $-12 \%$ & $-27 \%$ & 28 & $-6 \%$ & $-19 \%$ \\
\hline 63 & $-4 \%$ & $-19 \%$ & 63 & $-6 \%$ & $-34 \%$ \\
\hline
\end{tabular}

Comparando-se os resultados apresentados nas Figuras 5 e 6, percebe-se, como previsto pela Curva de Abrams, que os corpos de prova produzidos a partir do traço $\mathrm{A}$, com relação $a / c=0,55$, apresentaram maiores resistências à compressão, quando comparados às amostras do concreto $\mathrm{B}$, com $a / c=0,60$. Verificou-se que, aos 28 dias, o concreto A atingiu $23 \%, 15 \%$ e $11 \%$ a mais de resistência em relação ao concreto B, para cura imersa, cura em saco plástico e cura ao ar, respectivamente.

Os resultados demonstram que as amostras submetidas à cura imersa em solução saturada de hidróxido de cálcio apresentaram as maiores resistências aos 28 dias, seguidas pelas que foram curadas em saco plástico e cura ao ar, independentemente da relação água/cimento utilizada nas dosagens. No caso do concreto A, as amostras curadas em saco plástico e ao ar apresentaram resistência $12 \%$ e $27 \%$ a menos do que as que sofreram cura imersa. Para o concreto B, esses percentuais foram de $6 \%$ e $19 \%$, respectivamente.

Ao analisar o comportamento da curva de resistência do concreto B submetido a cura ao ar (Figura 4), nota-se um arrefecimento da taxa de ganho de resistência entre os 28 e 63 dias, diferente do observado nas demais curvas. Aos 28 dias, a resistência média do concreto foi de 27,66 $\mathrm{MPa}$ e, até aos 63 dias, evoluiu para somente 29,16 MPa.

Ao analisar as resistências aos 3 e 7 dias dos concretos de ambas dosagens, percebe-se que as maiores resistências foram obtidas para os corpos de prova submetidos à cura em saco plástico. Além disso, nessas idades, observam-se as menores diferenças percentuais entre as resistências do concreto curado ao ar e imerso. Em contrapartida, a partir dos 14 dias, as maiores resistências médias foram observadas nos corpos de prova submetidos a cura imersa.

Observando a Tabela 5, nota-se que as diferenças percentuais entre as resistências dos corpos de prova submetidos a cura ao ar e à cura imersa, a partir dos 14 dias, foram significativamente elevadas. No concreto A, essa diferença alcançou $27 \%$ aos 14 e 28 dias e, no concreto B, a diferença percentual foi de $34 \%$ aos 63 dias. Já as amostras curadas em saco plástico, por sua vez, apresentaram pouca redução de resistência nas idades avançadas, se comparadas com aquelas submetidas à cura imersa. Para as amostras curadas em saco plástico, a maior diferença percentual em relação à cura imersa foi de $13 \%$, aos 3 dias, para o concreto $\mathrm{A}$, e de $9 \%$ aos 14 dias, para o concreto B.

Para avaliar o desempenho dos ensaios de resistência à compressão, realizou-se uma análise estatística, conforme o método do Anexo B da ABNT NBR 5739:2018. Os resultados mostram que a maioria dos grupos apresentou desempenho positivo (Tabela 6). Ressalta-se que os grupos avaliados como "deficiente" devem ser tratados com cuidado. 
Tabela 6 - Análise estatística dos resultados - ABNT NBR 5739:2018 (Anexo B).

\begin{tabular}{|c|c|c|c|c|c|c|c|c|c|c|}
\hline \multirow[b]{2}{*}{ ID } & \multirow{2}{*}{$\begin{array}{l}\text { Idade } \\
\text { (dias) }\end{array}$} & \multicolumn{3}{|c|}{ CI } & \multicolumn{3}{|c|}{ SP } & \multicolumn{3}{|c|}{$\mathbf{A R}$} \\
\hline & & $\begin{array}{c}f_{c m} \\
(\mathbf{M P a})\end{array}$ & $c v_{e}$ & Avaliação & $\begin{array}{c}f_{c m} \\
(\mathbf{M P a})\end{array}$ & $c v_{e}$ & Avaliação & $\begin{array}{c}f_{c m} \\
(\mathbf{M P a})\end{array}$ & $c v_{e}$ & Avaliação \\
\hline \multirow{5}{*}{ 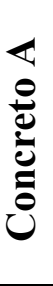 } & 3 & 14,21 & $5,9 \%$ & Razoável & 16,02 & $1,6 \%$ & Excelente & 13,61 & $2,6 \%$ & Excelente \\
\hline & 7 & 27,43 & $4,9 \%$ & Bom & 28,01 & $3,0 \%$ & Excelente & 24,39 & $4,5 \%$ & Bom \\
\hline & 14 & 36,91 & $0,1 \%$ & Excelente & 33,62 & $2,9 \%$ & Excelente & 27,08 & $8,0 \%$ & Deficiente \\
\hline & 28 & 41,94 & $0,9 \%$ & Excelente & 36,75 & $5,0 \%$ & Bom & 30,56 & $7,9 \%$ & Deficiente \\
\hline & 63 & 51,60 & $1,3 \%$ & Excelente & 49,35 & $2,1 \%$ & Excelente & 41,80 & $0,1 \%$ & Excelente \\
\hline \multirow{5}{*}{ 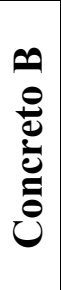 } & 3 & 11,42 & $6,6 \%$ & Deficiente & 11,91 & $7,8 \%$ & Deficiente & 10,74 & $2,3 \%$ & Excelente \\
\hline & 7 & 22,37 & $5,9 \%$ & Razoável & 22,81 & $0,1 \%$ & Excelente & 18,64 & $1,3 \%$ & Excelente \\
\hline & 14 & 28,73 & $4,0 \%$ & Muito bom & 26,23 & $4,4 \%$ & Bom & 23,77 & $3,4 \%$ & Muito bom \\
\hline & 28 & 34,16 & $4,9 \%$ & Bom & 32,00 & $0,2 \%$ & Excelente & 27,66 & $2,6 \%$ & Excelente \\
\hline & 63 & 44,48 & $3,0 \%$ & Excelente & 41,86 & $6,7 \%$ & Deficiente & 29,16 & $0,0 \%$ & Excelente \\
\hline
\end{tabular}

Para efeito de análise, tomou-se o resultado experimental de carga última obtida de um ensaio de flexão com uma viga de $5 \mathrm{~m}$ de comprimento, confeccionada com um dos concretos analisados. $\mathrm{Na}$ data do ensaio, o concreto estava com 33 dias de idade e a viga atingiu a carga última $P_{\max }=722,9 \mathrm{kN}$. Foram realizadas três simulações numéricas da viga referida, sendo que em cada uma o modelo constitutivo do concreto foi definido com o $f_{c m}$ obtido para cada método de cura considerado, de acordo com a EN 1992-1-1 (2010). Os resultados estão mostrados na Tabela 7.

Tabela 7 - Avaliação experimental da influência do tipo de cura na resistência à compressão do concreto numa estrutura real.

\begin{tabular}{|c|c|c|c|c|c|}
\hline Tipo de cura & $\begin{array}{c}f_{c} 33 \text { dias } \\
(\mathrm{MPa})\end{array}$ & $\begin{array}{c}P_{\max \text { num }} \\
(\mathrm{kN})\end{array}$ & $\frac{P_{\max }}{P_{\max , \mathrm{CI}}}-1$ & $\frac{f_{c}}{f_{c, \text { CI }}}-1$ & $\frac{P_{\text {max, num }}}{P_{\max , \text { exp }}}$ \\
\hline AR & 29,7 & 594,0 & $-8,7 \%$ & $-18,9 \%$ & $-18 \%$ \\
\hline SP & 34,5 & 637,6 & $-2,0 \%$ & $-5,7 \%$ & $-12 \%$ \\
\hline CI & 36,6 & 650,3 & $0 \%$ & $0 \%$ & $-10 \%$ \\
\hline$P_{\text {max } \text { exp }}=722,9 \mathrm{kN}$ (carga máxima atingida no ensaio experimental) \\
\hline
\end{tabular}

Observa-se, da Tabela 7, que a simulação numérica estimou a carga última com melhor aproximação do ensaio experimental com o $f_{c}$ medido das amostras com cura imersa. A pior aproximação numérica se deu para o $f_{c}$ das amostras com cura ao ar. E a simulação com o $f_{c}$ das amostras curadas em saco plástico chegou num resultado bom, próximo do obtido com o $f_{c}$ das amostras com cura imersa. A mesma tendência foi observada para outras 5 vigas ensaiadas à flexão no mesmo programa experimental (Petrauski, 2021).

\section{CONCLUSÃO}

Neste trabalho avaliou-se a influência de três diferentes métodos de cura na evolução da resistência à compressão do concreto: cura ao ar, cura em saco plástico e cura imersa. Um total de 72 amostras 
foram analisadas. Um dos objetivos era avaliar a prática comum em laboratórios de pesquisa de deixar amostras de concreto curarem ao ar, nas mesmas condições dos espécimes para experimentação.

Os resultados obtidos revelaram que a taxa de crescimento da resistência à compressão é consideravelmente menor para concretos curados ao ar, em relação à observada para cura imersa ou cura em saco plástico, confirmando as observações de Ferreira Junior (2003), Bardella (2005), Mehta e Monteiro (2006), Silva et al. (2011), Szeremeta e Silva (2013), Ribeiro et al. (2014), Marques (2017), Melo (2017), Figueiredo et al. (2019) e Assunção et al. (2021).

O $f_{c m}$ medido aos 28 dias para amostras curadas ao ar foi de $19 \%$ a $27 \%$ inferior ao de amostras que sofreram cura imersa. $\mathrm{O} f_{c m}$ medido aos 28 dias para amostras curadas em saco plástico ao ar foi de $6 \%$ a $12 \%$ inferior ao de amostras que sofreram cura imersa.

Uma comparação de resultados numéricos com resultados experimentais de ensaios de flexão com vigas mistas com vãos de 4 a 6 m demonstrou que o resultado da simulação numérica se aproxima mais do resultado experimental quando o modelo constitutivo do concreto é definido com o $f_{c}$ oriundo do concreto submetido a cura imersa.

As análises demonstraram que a cura em saco plástico conduz a uma evolução da resistência à compressão do concreto um pouco inferior mas muito próxima da observada quando o concreto é submetido a cura imersa, confirmando as observações de Assunção et al. (2021), de modo que, na falta de condições para realização de uma cura imersa, este método de cura é uma alternativa aceitável.

Os resultados também evidenciaram que a cura ao ar não conduz a bons resultados em relação ao concreto na estrutura real, mesmo em ambientes internos de laboratórios, indicando que as melhores estimativas da resistência do concreto são obtidas quando se considera a resistência à compressão medida de amostras curadas em ambiente saturado de água.

\section{REFERÊNCIAS BIBLIOGRÁFICAS}

ANDRADE, T. C. C. S. de. Avaliação do tipo de cura nas propriedades de concretos de pós reativos. 2015. 102 f. Dissertação (Mestrado) - Curso de Programa de Pós Graduação em Engenharia de Construção Civil, Setor de Tecnologia, Universidade Federal do Paraná, Curitiba.

ASSOCIAÇÃO BRASILEIRA DE NORMAS TÉCNICAS. NBR 5738: Versão Corrigida: 2016: Concreto - Procedimento para moldagem e cura de corpos de prova. Rio de Janeiro: ABNT, 2015. 9 p.

. NBR 5738: Moldagem e cura de corpos-de-prova cilíndricos ou prismáticos de concreto. Rio de Janeiro: ABNT, 1994. 9p.

. NBR 5739: Concreto - Ensaio de compressão de corpos de prova cilíndricos. Rio de Janeiro: ABNT, 2018. 9p.

. NBR 7211: Versão Corrigida: 2019: Agregados para concreto - Especificação. Rio de Janeiro: ABNT, 2019.9 p.

. NBR 16605: Cimento Portland e outros materiais em pó — Determinação da massa específica. Rio de Janeiro: ABNT, 2017. 4 p. 2001. $3 \mathrm{p}$

NBR NM 30: Agregado miúdo - Determinação da absorção de água. Rio de Janeiro: ABNT, 
. NBR NM 45: Agregados - Determinação da massa unitária e do volume de vazios. Rio de Janeiro: ABNT, 2006. 8 p.

. NBR NM 52: Agregado miúdo - Determinação da massa específica e massa específica aparente. Rio de Janeiro: ABNT, 2009. 6 p.

. NBR NM 53: Agregado graúdo - Determinação da massa específica, massa específica aparente e absorção de água. Rio de Janeiro: ABNT, 2009. 8 p.

. NBR NM 67: Concreto - Determinação da consistência pelo abatimento do tronco de cone. Rio de Janeiro: ABNT, 1998. 8 p.

. NBR NM 248: Agregados - Determinação da composição granulométrica. Rio de Janeiro: ABNT, 2003. 6 p.

ASSUNÇÃO, W. R. de; ALMEIDA, G. M. de; GOMES, L. G. Análise Estatística da Influência do Tipo de Cura na Resistência Mecânica do Concreto de Cimento Portland. RCT - Revista de Ciência e Tecnologia, [S.1.], v. 7, 2021.

BARDELLA, P. S. Avaliação das propriedades físicas e mecânicas de concretos produzidos com os cimentos Portland de alta resistência inicial e de alto-forno aditivados com sílica ativa curados termicamente. 2005. 222 f. Dissertação (Mestrado) - Curso de Pós-Graduação em Edificações, Faculdade de Engenharia Civil, Arquitetura e Urbanismo, Universidade Estadual de Campinas, Campinas, 2005.

EN 1992-1-1:2010. Design of concrete structures - Part 1-1: General Rules and Rules for Buildings. European Committee for Standardization. 2010.

FERREIRA JUNIOR, E. L. Avaliação de propriedades de concretes de cimento Portland de altoforno e cimento Portland de alta resistência inicial submetidos a diferentes condições de cura. 2003. 158 f. Dissertação (Mestrado) - Curso de Engenharia Civil, Universidade Estadual de Campinas, Campinas, 2003.

FIGUEIREDO, C. DO M.; ARAUJO, M. A.; BARBOZA, L. DA S.; SARTORTI, A. L. Análise da influência do método de aplicação da cura na resistência do concreto. Revista Tecnológica, v. 27, n. 1, p. 71-81, 2019.

HELENE, P. R. L. La Agresividad del Médio y Durabilidad del Hormigón. Hormingón, AATH, n. 10, p. $25-35,1983$.

LANSINI, B. Influência da temperatura de cura na resistência à compressão do concreto. 2016. 78 f. TCC (Graduação) - Curso de Engenharia Civil, Departamento de Engenharia Civil, Universidade Federal do Rio Grande do Sul, Porto Alegre, 2016.

MARQUES, M. B. de O. Cura seca, cura úmida, cura térmica: avaliação da eficiência na resistência à compressão do concreto. 2017. 64 f. TCC (Graduação) - Curso de Engenharia Civil, Centro de Engenharias, Universidade Federal Rural do Semi-Árido, Mossoró, 2017. 
MEHTA, P. K.; MONTEIRO, P. J. M. Concrete: Microstructure, Properties and materials. 3. ed. New York: McGraw-Hill, 2006. 684 p.

MELO, F. G. de S. Análise da influência do tempo de cura na resistência à compressão do concreto. 2017. 60 f. Monografia (Graduação) - Curso de Engenharia Civil, Departamento de Desenvolvimento de Ensino, Instituto Federal de Educação, Ciência e Tecnologia do Sergipe (Campus Aracajú), Aracajú, 2017.

PETRAUSKI, M. Avaliação numérico-experimental do comportamento de vigas mistas prémoldadas tipo crestbeam sujeitas a flexão simples. 2021. Tese de Doutorado em Engenharia Civil, Universidade Federal de Viçosa, Viçosa, 2021.

RIBEIRO, G. D.; GOMES, M. V.; VALIN JR, M. O. Influência da cura do concreto com e sem a utilização de lona plástica na resistência mecânica e absorção de água. In: Congresso Brasileiro do Concreto, 56, 2014, Natal - RN. Anais [...]. São Paulo: Ibracon, 2014.

SILVA, S. da; BIAZETTO, B. R.; CHIES, J. A.; SILVA, L. C. S. da. Análise da influência de diferentes processos de cura na resistência à compressão. In: Congresso Brasileiro do Concreto, 53, 2011, Florianópolis - SC. Anais [...]. São Paulo: Ibracon, 2011.

SILVA, E. S. da; MIRANDA, P. S. T.; SILVA, S. A. da; RODRIGUES, H. A. C.; ALCÂNTARA, P. B., BEZERRA, A. J. V. Influência da cura na resistência do concreto à compressão. In: Congresso Brasileiro do Concreto, 53, 2011, Florianópolis - SC. Anais [...]. São Paulo: Ibracon, 2011.

SZEREMETA, A.; Silva, N. L. da. Estudo da variação na resistência a compressão de concretos convencionais devido aos diferentes tipos de cura. 2013. 57 f. TCC (Graduação) - Curso Superior de Tecnologia em Concreto, Universidade Tecnológica Federal do Paraná, Curitiba, 2013. 